\title{
PESSOA, DIREITOS FUNDAMENTAIS E DIREITO DA PERSONALIDADE*
}

\section{José de Oliveira Ascensão}

\section{Sumário}

1 A "dignidade da pessoa humana". 2 Génese e significado dos direitos fundamentais. $3 \mathrm{~A}$ distorção dos direitos fundamentais. $\mathrm{O}$ plano internacional. $4 \mathrm{O}$ direito à felicidade. 5 Os direitos de personalidade e a sua evolução. 6 Uma crise de identidade. 7 A questão à luz da lei civil. 8 Direito e personalidade ôntica. 9 A vertente comunitária. 9 As insuficiências dos Direitos de Personalidade. 11 O Direito da Personalidade.

\section{Resumo}

A unanimidade aparente na afirmação da dignidade da pessoa humana como fundamento das sociedades contemporâneas esconde as maiores divergências. Os direitos fundamentais traduzem antes uma visão sem base ética, que lisonjeia o homem-massa pela ilusão de que tudo the é dado e nada lhe é pedido. Os direitos de personalidade sofrem distorção semelhante, ameaçando transformarse no reino egoísta da privacy e esquecer a dimensão da solidariedade. Mas sem base substantiva não se justifica o regime muito privilegiado de que disfrutam. Há que reencontrar a pessoa, retomando a linha que

\section{Abstract}

The apparent unanimity in the affirmation of the dignity of the person buman being as bedding of the societies contemporaneous hides the biggest divergences. The basic rights before translate a vision without ethical base, that flatters the man-mass for the illusion of that everything is given to it and nothing it is asked for to it. The personality rights suffer similar distortion, threatening to change them into the egoistic kingdom of privacy and to forget the dimension solidarity. But without substantive base if it very does not justify the privileged regimen of that they have. It has that to reencounter the person, retaking the line that if covered from the philosophy Greek and of the Christianity. The man is an autonomous

\footnotetext{
* Dedicamos este escrito à memória do Prof. Doutor João de Matos Antunes Varela. Não tivemos com ele particular ligação e estivemos muitas vezes em divergência. Mas isso nada retira à grande admiração que por ele temos, como um dos maiores juristas portugueses do nosso tempo. Por isso nos choca o silêncio que se abateu sobre a notícia da sua morte. Por nossa parte, desde já deixamos este trabalho disponível para o Livro que, esperamos, venha a ser elaborado em memória do Mestre.
} 
se percorreu a partir da filosofia grega e do cristianismo. O homem é um ser autónomo com fins próprios, responsável pela sua autorealização. Esta não se faz na associabilidade, contra os outros, mas em solidariedade, com os outros. Propõe-se que se transite dos direitos de personalidade, logo na origem marcados por distorção individualista, para um englobante Direito da Personalidade, com direitos e deveres centrados na essência ontológica e ética da pessoa humana e na integração comunitária dela constituinte.

\section{Palavras-chave}

Dignidade da pessoa humana. Direito da personalidade. Direitos Fundamentais. with proper ends, responsible being for its selfrealization. This does not become in the associability, against the others, but in solidarity, with the others. It is considered that if it transits of the personality rights, then in the origin marked by individualistic distortion, for a Right which involves the Personality, with rights and duties centered in the ontological and ethical essence of the person human being and in the communitarian integration of constituent it. The apparent unanimity in the affirmation of the dignity of the person human being as bedding of the societies contemporaries hides the biggest divergences. The basic rights before translate a vision without ethical base, that flatters the man-mass for the illusion of that everything is given to it and nothing it is asked for to it. The personality rights suffer similar distortion, threatening to change themselves into the egoistic kingdom of privacy and to forget the dimension solidarity. But without substantive base it does not justify the privileged regimen of that they have. It has that to research the person, retaking the line that if covered from the philosophy Greek and of the Christianity. The man is an autonomous with proper ends, responsible being for its self- realization. This does not become in the associability, against the others, but in solidarity, with the others. It is considered that if it transits of the personality rights, then in the origin marked by individualistic distortion, for a Right which involves Personality, with rights and duties centered in the ontological and ethical essence of the person human being and in the communitarian integration of constituent it.

\section{Key words}

Dignity of the buman person. Right of personality. Fundamental rights. Basic Rights.

\section{A “dignidade da pessoa humana"}

Aparentemente, as nossas sociedades, particularmente as sociedades ocidentais, repousam sobre uma base substancial unívoca e forte.

Essa base é a pessoa humana.

Situando-nos no passado próximo, avulta o movimento que se desenvolveu a partir da guerra de 1939-45. Os horrores então revelados fizeram sentir as insuficiências do 
positivismo dominante e os perigos de um poder estatal sem limites, ainda que fundado na vontade ou no consentimento das maiorias.

Esses limites poderiam ser encontrados na forma democrática do poder, na estrutura de controle dos órgãos de soberania, na participação directa dos cidadãos...

Mas havia que descer mais fundo e procurar assegurar conteúdos mínimos que se impusessem ao próprio Estado e às maiorias ${ }^{1}$. A soberania não era totalitária, antes de mais porque domínios da vida individual e social eram pré-dados e subtraídos à intervenção política.

O conteúdo material nuclear que se desenvolveu foi justamente representado pela pessoa humana.

Esta, nas suas vastas implicações, estaria ao abrigo da actividade do Estado; mais do que isso, seria ela afinal um fundamento de toda a estrutura política, que seria colocada ao seu serviço.

Esta prioridade surge lapidarmente expressa na primeira frase da Constituição de Bona: Die Würde des Menschen ist unantastbar ${ }^{2}$. Declarações semelhantes, assentes na ideia da dignidade da pessoa humana, repetiram-se depois em outras constituições, como a portuguesa actual, embora enfraquecidas pela mistura deste princípio fundamental com outros de carácter bem mais precário ou instrumental ${ }^{3}$.

Análogas declarações se encontram em textos internacionais. Salienta-se a "Declaração Universal dos Direitos do Homem” de 1948, não obstante tratar-se de simples resolução da Assembléia Geral da Organização das Nações Unidas. Portanto, aparentemente, esse princípio tornara-se de Direito Internacional, universalizado pela sucessiva admissão na ONU de tendencialmente todos os Estados do mundo.

É realmente uma carreira triunfal. Mas esconde muito de ilusório4.

A cobertura mundial por princípios que ignoram o espaço e o tempo, que vigorarão do Canadá ao Iémen e à Mongólia, só pode fazer-se sob o manto dum silêncio conveniente e cúmplice.

\footnotetext{
${ }^{1}$ Não basta invocar o "constitucionalismo global” ou fórmula semelhante, bastando-se com o facto de aqueles elementos estarem consagrados na constituição. A constituição dá sempre apenas um fundamento relativo, porque ela própria carece de ser fundamentada.

${ }^{2}$ A dignidade da pessoa humana é inviolável (art. 1).

${ }^{3}$ A Constituição francesa não proclama este princípio, mas o Conselho Constitucional proclamou em 1994 o princípio da salvaguarda da dignidade da pessoa (cfr. Frank Moderne, La dignité de la personne comme principe constitutionnel dans les Constitutions portugaise et française, in "Perspectivas Constitucionais. Nos 20 Anos da Constituição de 1976" (coord. Jorge Miranda), Coimbra Editora, 1996, 209 e 226227). Fala-se num “direito fundamental à dignidade", mas não nos parece procedente. Um direito à dignidade em si apela para aspectos muito mais limitados, relacionados com a consideração social devida a cada pessoa, ficando muito longe da força axiológica do princípio do primado da dignidade da pessoa.

${ }^{4}$ A URSS absteve-se, bem como a Arábia Saudita, o único país árabe representado ao tempo.
} 
O próprio modo como foi acolhida nos países ocidentais obriga a interrogar-nos sobre o significado das fórmulas adoptadas.

O positivismo não desapareceu em 1945. Pelo contrário, nas suas formas mais extremas, fora já elaborado de modo a ser insensível às variações históricas do poder 5 . Positivisticamente, a dignidade da pessoa humana só pode ser entendida como fórmula vazia, adaptável a todos os conteúdos. A discussão actual em torno da Bioética é bem característica, uma vez que no seio dos países que mais longe levaram o desenvolvimento dos direitos fundamentais se seguem as posições mais variadas em temas em que é a própria pessoa humana, na sua realidade ontológica, que está em causa.

Procuremos compreender. A dignidade da pessoa humana traduziu-se historicamente pela afirmação dos direitos fundamentais. Deitemos então um olhar retrospectivo às origens, para apurar o que podem representar estes como sustentáculo da pessoa humana que dizem servir.

\section{Génese e significado dos direitos fundamentais}

Partimos das Declarações dos Direitos do Homem e do Cidadão, tal como se formularam no séc. XVIII. Traduzem a resposta a que se chegou à questão do Estado, a que o indivíduo se subordinaria pelo contrato social; por este justamente o Estado compromete-se a respeitar os direitos dos cidadãos. Os direitos assegurados, por isso fundamentais, tomam uma feição de direitos contra o Estado, de que se não libertaram até hoje. O Estado serve, mas há que refreá-lo; por isso os direitos fundamentais são essencialmente defensivos ${ }^{6}$.

O liberalismo/individualismo do séc. XIX leva ao extremo esta visão, acentuando sobretudo a esfera privada (origem da privacidade), que é mantida ao abrigo da intervenção do Estado.

$\mathrm{Na}$ base filosófica desta concepção continua a estar a Razão criadora do enciclopedismo do séc. XVIII. Obedece assim ao postulado da abstracção da realidade histórica e à imposição dum modelo que se pretende universal. Tudo isso chega afinal até hoje, com adoçamentos que não alteram a essência.

Adoçada foi particularmente, sobretudo no séc. XX, a índole dos direitos fundamentais como direitos contra o Estado, mediante a introdução doutros objectivos. Mas é sempre basicamente o estatuto do indivíduo dentro da pólis que está em causa. Chega-se a modalidades exacerbadas de garantia, muito propícias a um florescer do sistema capitalista a que efectivamente servem.

\footnotetext{
${ }^{5}$ É, expressamente, a posição da "Teoria Pura do Direito".

${ }^{6} \mathrm{E}$ participativos, na maior parte dos casos.
} 
Mas não é esta a nossa questão. A nossa questão é antes a de saber se pelos direitos fundamentais se realiza efectivamente a tutela da pessoa. Se podemos falar de uma identidade entre direitos fundamentais e direitos de personalidade.

A consagração constitucional da dignidade humana e dos direitos fundamentais representa a garantia dos direitos de personalidade?

É desde logo claro que não há identificação de categorias. Os direitos fundamentais vão muito mais longe. Atribuem direitos a organizações, que não são já pessoas. Espraiam-se por direitos sociais, económicos e culturais, que não são direitos de personalidade. Abrangem as garantias, que em si não são direitos de personalidade.

Não é necessário ir mais longe para negar a identificação. Mas a questão pode retomarse variando um pouco a colocação. Não sendo embora idênticos, poderá dizer-se que os direitos fundamentais constituem um círculo mais amplo, que compreende em si os direitos de personalidade? De maneira que os direitos de personalidade receberiam já tutela positiva pela sua integração nos direitos fundamentais?

Poderíamos sustentar a resposta negativa mediante o confronto do elenco dos direitos de personalidade, previstos no Código Civil, com os direitos fundamentais. Verificaríamos que, embora as matérias que são conteúdo dos direitos de personalidade estejam também contempladas em geral entre os direitos fundamentais, a coincidência não é total: algo fica de fora. E a conclusão poderia ser reforçada com a observação, certeira, que o regime estabelecido no Código Civil não coincide com o regime da Constituição.

Mas é mais importante que a análise seja dirigida ao que está essencialmente em causa no direito fundamental e no direito de personalidade.

No centro do direito de personalidade deve estar a defesa da pessoa humana como tal. Sem isto, a categoria seria supérflua.

Já semelhante objectivo só lateralmente pode ser prosseguido pelos direitos fundamentais. Nem sequer se pode dizer que todo o direito de personalidade, materialmente assim considerado por representar imposição da personalidade ôntica, deva por isso ser acolhido como direito fundamental.

É verdade que a Constituição admite no art. 16/1 a extensão da categoria “direitos fundamentais" a quaisquer outros "constantes da lei". Levar-nos-ia muito longe interpretar essa fórmula ambígua. Mas de todo o modo não se vê maneira de fazer equivaler "direito de personalidade" a "direito fundamental constante da lei". São categorias de núcleo necessariamente diferente.

Também o art. 17 dispõe que o regime dos direitos, liberdades e garantias se aplica aos enunciados no título II e "aos direitos fundamentais de natureza análoga". Não se pode porém pretender que os direitos de personalidade se integrariam como tal nesta categoria, porque vimos que nem sequer passam na prova de qualificação como direitos fundamentais. 
Tão-pouco a tentativa de reconduzir os direitos fundamentais a manifestações do princípio da dignidade da pessoa humana parece poder ser acolhida. Realizou-a Vieira de Andrade ${ }^{7}$ mas encontrou a crítica radical de Gomes Canotilho, que rejeita até a valia da distinção entre direitos fundamentais materiais e direitos fundamentais formais ${ }^{8}$. De facto, o fulcro dos direitos fundamentais segundo a Constituição não está no desenrolar das implicações da dignidade da pessoa humana, mas na conformação de relações que se desenvolvem na sociedade politicamente organizada. Aspectos decorrentes da personalidade humana que não estiverem contemplados nas leis não podem ser integrados no conceito de direito fundamental. Muito menos podem aspirar ao regime particularmente protector que a Constituição assegura aos direitos, liberdades e garantias (art. 18), desde logo porque só poderia atribuir-se "natureza análoga" aos que fossem especificamente consagrados: doutra maneira abrir-se-ia uma incerteza insuprível na determinação dos limites da categoria ${ }^{9}$.

\section{A distorção dos direitos fundamentais. $O$ plano internacional}

As considerações até aqui produzidas são essencialmente técnicas. Não dispensam uma consideração substancial da evolução verificada no âmago dos direitos fundamentais.

Se por um lado se abrem em leque os direitos fundamentais e isso permite integrar no seu âmbito direitos de personalidade que não eram contemplados nas declarações primitivas, por outro a própria noção de direito fundamental sofre uma distorção que cada vez mais a leva a afastar-se da idéia nuclear da defesa da personalidade.

A vocação das listas constitucionais de direitos fundamentais torna-se cada vez mais a de consolidar as reivindicações de grupos de interesses - indo portanto num sentido diametralmente oposto ao da consagração nuclear do primado da pessoa.

A ampliação do número de direitos fundamentais tem como consequência a diluição da categoria, cada vez mais só formalmente definível. Cada novo direito apaga mais um tanto a marca do que é verdadeiramente fundamental. E, com essa degradação, consagram-se como direitos fundamentais aspectos que exprimem pretensões de grupos ou classes que não atendem, ou inclusivamente podem ser contrários, à dignidade da pessoa humana ${ }^{10}$.

\footnotetext{
${ }^{7}$ Em Os Direitos Fundamentais na Constituição Portuguesa de 1976 (Almedina, 1983, 78 e segs.), que procura um critério de substância: podem direitos que não constam da Constituição ser direitos fundamentais, tal como podem direitos que constam da Constituição não ser materialmente direitos fundamentais.

${ }^{8}$ CANOTILHO, J. J. Gomes. Direito constitucional e teoria da Constituição. 5. ed. Almedina, 2002, p. 404-405.

${ }^{9}$ Cf. sobre este ponto o nosso Direito Civil. Teoria geral. 2. ed. Coimbra: 2000, p. 53-55. (I - Introdução. As pessoas. Os bens). Há entre os constitucionalistas posições diferenciadas sobre este ponto.

${ }^{10}$ Cf. OTERO, Paulo. A democracia totalitária. Principia, 2001, n. 8.2.3.
} 
A evolução no plano internacional é talvez ainda mais preocupante.

A multiplicação de declarações não serve propriamente os direitos humanos, mas os propósitos específicos das organizações de que promanam, ou de quem as domina.

A afirmação dos direitos do homem serve como pretexto para a ingerência dos países dominantes noutros países: porque, não por razões contingentes mas por razões estruturais, não é possível supor um uso da força no domínio internacional que não seja uma emanação dos mais fortes. Mas não são os mais fracos quem tem maior propensão para violar os direitos humanos, são aqueles que têm a segurança da impunidade. Fortalecem-se assim as grandes potências com o papel de juizes da correcção dos procedimentos dos outros países.

Serviu também de pretexto para a criação de tribunais internacionais no rescaldo das guerras. Mas os tribunais internacionais são tribunais para julgar os vencidos. A civilização realizou um progresso, quando a vitória militar deixou de ser selada pela execução dos reis derrotados. Hoje regride-se, por invocação dos direitos humanos. Dá a satisfação hipócrita da punição dos desmandos, freqüentemente reais, dos inimigos, à custa da violação de um princípio fundamental de justiça, que consiste na isenção do julgador. Não há serviço dos direitos humanos, porque nenhum tribunal político pode fazer justiça ${ }^{11}$.

É por isso ambíguo todo o progresso internacional dos direitos humanos. Na prática, coexiste com a tolerância das violações mais gritantes em tantas partes do mundo.

Talvez os objectivos tenham sido logo de início outros. É impressionante o relevo que nessas declarações se dá à propriedade. Com todo o respeito que a instituição merece, ela não possui tanta densidade ética que leve a dar-lhe um lugar prioritário. Tem razão a Constituição portuguesa, não a inscrevendo entre os direitos, liberdades e garantias.

E vão-se imiscuindo marcas dos lobbies dominantes, que maculam a pureza pretendida das declarações. Assim, a DUDH dispõe no art. 27/2 que "todos têm direito à protecção dos interesses morais e materiais ligados a qualquer produção científica, literária ou artística da sua autoria". Apesar do carácter moderado da fórmula, ficamos espantados ao pensar que o conteúdo mínimo de protecção dos indígenas da Nova Guiné ou das mulheres em regimes de fundamentalismo islâmico passa prioritariamente por uma

\footnotetext{
11 Também na Comunidade Europeia a distorção se verifica. Foi aprovada numa Carta dos Direitos Fundamentais da União Europeia (2000). Porquê, se os países comunitários estão entre os que levam mais longe a protecção dos direitos fundamentais? Não é para fazer progredir a protecção da pessoa na Comunidade, mas para dar um novo passo no sentido da transformação da Comunidade num Estado. Com base no entendimento que uma declaração de direitos é um elemento fundamental duma Constituição, a Carta foi o prelúdio do projecto de Constituição Europeia. Os direitos fundamentais foram assim instrumentalizados, ao serviço de objectivos outros que nada têm que ver com a protecção da pessoa.
} 
152 protecção, também material, de interesses ligados à sua produção intelectual. Ou tratarse-á de interesses ligados à indústria de copyright de outrem?

\section{$4 \mathrm{O}$ direito à felicidade}

Em tudo isto está subjacente a visão da pessoa que está na origem das Declarações de Direitos do Homem.

A pessoa que se tem em vista é o indivíduo descaracterizado, vazio, tal como resulta da visão formal e atomística do séc. XVIII.

É o cidadão que quer assegurar um lugar imune a intervenções públicas, o indivíduo a quem se outorga a liberdade e o voto, mas que está eticamente esvaziado, porque esse ponto não encontra cabimento no contrato social.

É também no séc. XVIII que surge o entendimento que a finalidade do poder é a felicidade dos povos.

Parece hoje perfeitamente normal. Está presente em cada discurso dos políticos. O Estado serve seres que só têm direitos e não têm deveres, para lhes proporcionar a felicidade.

Mas não é tão natural assim. Até ao séc. XVIII não era essa a linguagem usada. Até porque o cidadão tinha deveres, e isso não era explicável através de um objectivo centrado na felicidade.

Remontemos mais longe. Vamos ao Evangelho. Debalde se procura a referência à felicidade: não consta ${ }^{12}$. Os três grandes objectivos que se apontam à existência humana são a paz, a alegria e a vida. Nunca se refere à felicidade, que aliás é uma ilusão num ser que a cada dia está mais próximo da morte ${ }^{13}$.

Mas não foi essa a filosofia do séc. XVIII. O homem só tem direitos e não deveres, e o Estado tem por função assegurar-lhe a felicidade.

O individualismo-liberal recebe com naturalidade esta visão, que transmite ao séc. XX. E hoje vivemos o culminar deste processo. O indivíduo tem direito a tudo. Cada dia se proclamam mais direitos fundamentais. Falta só um, que apenas não foi outorgado por uns restos de pudor: o direito à felicidade. Seria esclarecedor. Mas é duvidoso que surja, porque abriria demasiado o jogo.

De facto, a realidade desmente. Por mais que se proclame como objectivo a felicidade, não há felicidade. O empenho da sociedade passa então a ser o de forjar constantemente sub-rogados, que disfarcem a desconexão entre a promessa e a realidade.

\footnotetext{
${ }^{12}$ Nem feliz, ou termos relacionados.

${ }^{13} \mathrm{O}$ "ser para a morte", se a esperança estiver ausente. 
O sub-rogado principal está na lisonja. O cidadão é colocado no papel de cliente, que a sociedade serve. $\mathrm{O}$ cliente tem sempre razão. $\mathrm{O}$ lema da sociedade passa a ser: Você merece.

A lisonja está por todo o lado. Está antes de mais na publicidade, o grande meio de (des)educação da sociedade de massas. Só são oferecidas vantagens. Fomenta os piores sentimentos, a inveja, a luxúria, a ostentação...

Está nos meios de comunicação social, que dependem das audiências ${ }^{14}$. Os programas são ao gosto do destinatário. Por isso chegámos ao nível vil dos nossos programas de massas, sob o olhar vigilante da moribunda Alta Autoridade para a Comunicação Social.

Está enfim no discurso político. Tudo se promete. E embora a felicidade não chegue, há a segurança da impunidade, porque o embotamento público é já tão grande que dá a certeza que o método produz sempre efeito. Se houver contradição com as realidades, basta prometer mais forte na eleição seguinte.

Espraiámo-nos um pouco, mas atingimos o ponto onde pretendíamos chegar. Os direitos fundamentais não são um porto seguro a que possamos ancorar a defesa da pessoa. Seguem uma trilha própria e dúbia. Não se pode prescindir deles para esta defesa, mas haverá que procurar algures o núcleo da afirmação da pessoa na ordem jurídica.

\section{Os direitos de personalidade e a sua evolução}

Se os direitos fundamentais não oferecem o apoio de que carecemos, voltemo-nos para os direitos de personalidade.

Também estes nos surgem na linha aberta pelos oitocentistas direitos do Homem, de que representam uma derivação - embora o Homem fosse aí a Humanidade, como abstracção, e não a totalidade que é representada por cada pessoa. Mas tiveram dificuldade em ser acolhidos no Direito Privado. Ainda o BGB alemão, de 1900, os não compreendia.

Vão-se impondo porém progressivamente no séc. $\mathrm{XX}^{15}$. Têm o seu ponto mais alto na segunda metade do século, dentro do humanismo personalista que se expandiu por sobre as ruínas da guerra.

Oferecem a dificuldade de coordenação com os direitos fundamentais, pois para muitos representariam uma duplicação destes. Mas os códigos civis mais recentes não os dispensam. Desenvolve-se conseqüentemente a teorização dos direitos de personalidade, impulsionada pelo regime especialmente privilegiado que as leis que os contemplam lhes outorgam.

\footnotetext{
${ }^{14}$ Porque destas por sua vez depende a publicidade que angariam.

${ }^{15}$ Derrubando a corrente que considerava contraditória a existência de direitos sobre si mesmo.
} 
Manifesta-se também aqui a tendência da ampliação crescente do círculo dos direitos previstos. Podem ser empolados ao ponto de se confundirem com os direitos pessoais. E mais ainda, podem passar a incluir também direitos de pessoas colectivas: é a posição tomada entre nós por Rabindranath Capelo de Sousa ${ }^{16}$.

Surge assim o que podemos chamar a crise de identidade dos direitos de personalidade. Com isto verificamos que afinal a concordância prática na pessoa, que apontámos logo de início, esconde um mundo de problemas.

A pessoa, como dado ontológico, poderia dar um apoio seguro a esta categoria. Mas o positivismo, que não morreu, não pode aceitar esta premissa. Terá então de encontrar para ela uma explicação positiva, que só poderia estar na noção jurídica de pessoa. Mas a noção jurídica de pessoa abrange a própria pessoa colectiva. O que resta então como traço que explique a identidade substancial que aparentava ter esta categoria de direitos?

O questionamento torna-se mais preocupante ainda se considerarmos as correntes que se designam pós-modernas. Abandona-se o que se chama as certezas modernas e põe-se radicalmente em causa a possibilidade de interferência de qualquer verdade no mundo jurídico (desde logo porque se exclui que esta se conceba ou que a ela se possa elevar o espírito humano). O tema passa a ser o da ordenação da convivência num mundo em que nada se pode apresentar como verdadeiro: a sociedade passa a assentar então sobre este agnosticismo radical. Terá assim a ordenação social a estabelecer de repousar exclusivamente nos consensos, até onde for possível, ou na elaboração de esquemas que quebrem as divergências; mas nada se pode afirmar sobre os conteúdos. O empenhamento desta corrente passa a dirigir-se à demonstração antes de mais que nada se pode afirmar como verdadeiro, para sobre essa base idealizar a correspondente convivência humana.

Estas orientações devem ser encaradas em dois escalões: na pressuposta incognoscibilidade ou mesmo inexistência da verdade e nas conseqüências que daí se retiram.

Impressiona realmente que, após tantos séculos de primado de Sócrates sobre os sofistas, a doxa retorne com tal força que os talentos dos filósofos se esgotam na inglória batalha de demonstrar que não há verdade, ou está fora do alcance humano.

Não havendo verdade, também não há diálogo. O diálogo só é possível pela admissão de um denominador comum objectivo que seja ponto de referência para as partes. Sem esse ponto de referência, não há diálogo, há monólogos ${ }^{17}$. Ou então haverá o diletantismo, o divertimento mental sem objectivo, porque não se dirige a nada.

\footnotetext{
${ }^{16}$ O Direito Geral de Personalidade, Coimbra Editora, 1995. Temos aí o direito de personalidade sem pessoa ontológica. Tudo se reduz à categoria funcional do sujeito de situações jurídicas.

${ }^{17}$ É o diálogo de surdos a que tanto se assiste, pela falta de respeito pelo outro.
} 
Mas se quem afirma algo não admite a referência à verdade, toda a afirmação é incoerente. Não é só a concepção da convivência a que porventura chegue ${ }^{18}$, é desde logo o ponto de partida: a incognoscibilidade/inexistência da verdade. Porque se isso é proclamado como verdade, então afinal sempre há uma verdade, ainda que negativa. Pelo que quem assim pensa só não é contraditório se estiver calado ${ }^{19}$.

E de facto, como observou por exemplo Arthur Kaufmann, é contraditório que quem considera que o espírito humano tem capacidade para racionalmente se elevar à negação da verdade, não admita que esse mesmo espírito possa progredir positivamente no conhecimento da verdade das coisas.

Há um ponto em que o acordo está à vista: o espírito humano não pode captar a verdade integral. Por isso mesmo é humano, e não divino. Todo o conhecimento humano é parcelar. Acrescentaríamos que nem sequer podemos esperar que seja progressivo, no sentido que se caminharia para uma aproximação cada vez maior da verdade por acumulação, digamos assim, graças aos aspectos parcelares sucessivamente alcançados. Isso é válido na caminhada do espírito individual para a sabedoria, se para isso for conduzida, mas não é transferível para o percurso histórico da humanidade. Porque a realidade de que cada época se pode aperceber é limitada e constantemente variável, e o homem só pode procurar a verdade nas condições concretas da sua existência. Nem progressivamente poderia aspirar a uma verdade total.

O homem está assim condenado a conviver sempre com a incompleição e com o erro. A incompleição, quer dizer, a condição histórica limitadora do ponto de vista, é insuperável. E o erro?

O erro, em abstracto, é insuperável também. Mas se não se pode ser perfeito, podese ser menos imperfeito. Há que observar, com Karl Popper, que o diálogo, pela demonstração do erro, se não nos assegura a verdade, permite pelo menos que se melhore: que se fique menos errado. O homem pode aperfeiçoar-se pela busca da verdade, particularmente pelo exercício do diálogo.

Na vida espiritual, dizia Max Scheler, nada nos é dado, tudo nos é proposto. A busca da verdade pertence à vida espiritual. A verdade não nos é dada, antes exige um empenhamento sem fim da sua busca. Mesmo com as luzes da razão e da consciência, a verdade não é um pronto a servir ao nosso alcance; todo o avanço é o prémio do combate que travamos para a alcançar. É esse combate que é proposto a todos e exigido a cada pessoa como preço da aproximação da verdade.

Sem a referência à verdade, a ordem jurídica é um logro. Esta apresenta-se-nos antes de mais como fundada numa ordem objectiva, cujo conhecimento se pode ir desvelando. Se só há opiniões e não há verdade, o direito exprime apenas a maior força

\footnotetext{
${ }^{18}$ Seja jurídica ou outra.

${ }^{19}$ Dizia Hegel que limitar a razão com o raciocínio é querer nadar sem entrar na água. 
156 de quem detém o poder, porque a opinião que for consagrada não pode pretender nenhuma fundamentação racional ${ }^{20}$.

É como uma ordem racional e objectivamente controlável que o Direito se nos apresenta. O seu pressuposto é a possibilidade da solução correcta do caso. Mas só se essa solução for racional e objectivamente controlável o sistema tem defesa.

Por isso temos a estrutura judicial dos recursos. Se tudo se reduzisse à opinião, que sentido tinha a encenação dos julgamentos nas instâncias? Mais valia apresentar logo o caso à decisão de quem detém a vontade mais forte, que resolveria em definitivo. Mas porque se busca a decisão correcta, logo verdadeira, a solução é procurada primeiro nas instâncias, mas pode ser racionalmente controlada através dos recursos por quem deve ter maior saber e experiência. Não se impõem opiniões, apura-se a correcção da decisão emitida à luz do sistema ${ }^{21}$.

\section{Uma crise de identidade}

Partimos da observação da existência aparente duma concordância prática universal na pessoa humana, e sua inerente dignidade, como o mais forte esteio das actuais sociedades - pelo menos das sociedades ocidentais. Mas a reflexão sobre os direitos fundamentais revelou-nos que essa concordância escondia graves divergências.

O mesmo se verifica quando se examinam os direitos de personalidade - apesar de estes se centrarem directa e exclusivamente, por definição, sobre a própria personalidade humana. Surge o que podemos chamar a crise de identidade desta categoria.

Já não são só os desvios que levam a uns dissonantes direitos de personalidade de pessoas colectivas. Procede-se a toda uma extensão a matérias que nada têm que ver com a defesa da pessoa humana. É assim que por invocação do direito à imagem se assiste à proibição da utilização não autorizada da imagem de futebolistas ou gente do espectáculo. Direito da personalidade, no que respeita a um exclusivo sobre imagens que se exibem perante milhões de pessoas? Direito da personalidade, transformado em rede para captar mais dinheiro?

\footnotetext{
${ }^{20}$ Poderá no máximo invocar em seu abono a correcção dos processos que levaram à sua formação. Por isso surgem as teorias procedimentais da verdade.

${ }^{21}$ Poderia ainda deslocar-se o eixo da realização do Direito para a decisão concreta: o Direito seria acto, e não ordenamento. A verdade desta posição está em que o Direito, visto como ordem jurídica, engloba os actos. Porém, se fosse visto exclusivamente como acto, perderia a capacidade de englobar a ordem normativa, que é do Direito elemento integrante essencial. Sem nos determos neste ponto, limitamonos a observar que semelhante entendimento não se presta a captar a realidade do Direito. A acção é intrassubjectiva, o Direito é intersubjectivo. A acção surge integrada na ordenação de conjunto, particularmente na relação social. O Direito não se basta com a análise e valoração das subjectividades intervenientes.
} 
O individualismo deixou também uma marca muito forte nos direitos de personalidade que se apresentam. Culmina na privacy norte-americana, que se traduz como o "direito de estar só". Entendido nestes termos é um direito associal, que em si nada tem que ver com o desenvolvimento da pessoa humana. Do not disturb...

É visível o deslizar dos direitos de personalidade num sentido individualista, em que a solidariedade está de todo ausente. O indivíduo vira-se contra a sociedade. Admitese que não queira ser perturbado, mas que tem o direito de personalidade a ver com isto?

O mais grave de tudo está nas consequências que se tiram, e que podem chegar a ser consequências que lesem a pessoa, afinal. Também aqui penetra o direito à felicidade, que para se realizar tem de ignorar a infelicidade do outro. Em tantos domínios, que os meios de comunicação social buscam e realçam constantemente.

Por que o aborto ser livre só durante 10 ou 12 semanas? A personalidade da mulher não exige que o seja sempre?

E a geração dum segundo filho para dar órgãos que não sejam objecto de rejeição pelo 1. ${ }^{\circ}$ filho, que deles carece?

E a eutanásia, reclamada como direito dos que estão em situação de sofrimento?

No meio de tantas interrogações, algo se torna claro: a chave da solução está sempre na própria noção subjacente de pessoa. Enquanto esta não for esclarecida, todos os equívocos são possíveis.

\section{A questão à luz da lei civil}

Suportará porém a lei positiva esta fundamentação substancial na pessoa?

Dissemos já que sim, baseando-nos no fundamento constitucional na dignidade da pessoa bumana. Esta não pode sem atropelo à própria Constituição ser entendida em sentido formal.

Mas o mesmo há que dizer à luz da demarcação dos direitos de personalidade pelo Código Civil.

O art. 70/1 CC usa a fórmula: "A lei protege os indivíduos contra qualquer ofensa ilícita ou ameaça de ofensa à sua personalidade física ou moral". A referência a "indivíduos" destina-se a excluir as pessoas colectivas.

Deste princípio geral tem-se inferido a generalidade da protecção. Daqui deriva que os direitos de personalidade são atípicos. Este é um entendimento que, seja qual for a fórmula adoptada, não sofre contestação. Admite-se assim a existência de outros direitos de personalidade, além dos que vêm previstos na lei.

Isto parece evidente; mas esconde uma realidade muito profunda, que não cremos ter sido devidamente valorada. 
Os direitos de personalidade são direitos absolutos. Os direitos absolutos, porque vigoram erga omnes, são um numerus clausus, para que não aconteça que terceiros sejam surpreendidos ao verificarem estar vinculados por direitos que desconheciam.

Não obstante, os direitos de personalidade, sendo absolutos, são atípicos. Porquê tão grande singularidade?

Por que se pressupõe justamente que tutelam a pessoa. E a pessoa, nos seus aspectos fundamentais (que são justamente o objecto destes direitos) é uma realidade que todos conhecem, porque se impõe por natureza ao conhecimento de todos.

Isto significa que no âmago destes direitos está a pessoa ontológica, e que é em homenagem e por decorrência dela que se estabelece este regime verdadeiramente excepcional.

Daqui derivam várias consequências, além do carácter atípico dos direitos de personalidade:

1. A protecção fortíssima de que estes direitos gozam, sem paralelo com quaisquer outros. Assim, os meios de reacção a violações ou ameaças são os adequados (art. 70/ 2 CC), estejam ou não previstos particularmente na lei.

2. Só são objecto dos direitos de personalidade aspectos fundamentais da pessoa, pois só esses podem pretender reconhecimento por todos e disfrutar desta tutela acrescida. Isto nos leva a distinguir nos tipos de direito de personalidade admissíveis três zonas:

- o núcleo, que merece protecção em qualquer caso

- a periferia, que abrange aqueles aspectos que, estando embora formalmente compreendidos num tipo, não têm que ver com a personalidade ôntica: seja o caso de aspectos banais da vida privada que escapam ao objectivo substancial da defesa da intimidade pessoal. Esses, embora formalmente compreendidos, não são conteúdo do direito de personalidade e não beneficiam portanto do estatuto deste

- a orla, que é constituído por aquelas situações em que a personalidade está implicada mas com menor significado que nos aspectos nucleares. São estas que dão o conteúdo básico do art. 80/1 CC: a limitação voluntária ao exercício dos direitos é permitida, se não for contra princípios de ordem pública ${ }^{22}$. Todavia, continuam a representar direitos de personalidade e por isso estão ao abrigo da regra excepcional do n. ${ }^{\circ} 2$ : com a obrigação para quem o faz de indemnizar os prejuízos causados.

3. Enfim, e isto é essencial - apelam para uma noção substancial de pessoa humana, como a chave do âmbito da categoria.

A ela há pois que recorrer, pois nos é imposto quer pela natureza das coisas quer pela lei positiva.

\footnotetext{
${ }^{22}$ Mais correcto, no nosso entender, teria sido apelar para a cláusula geral dos bons costumes, e não para a ordem pública.
} 
A pessoa manifesta-se antes de mais na sua individualidade biológica. Sobre essa se desenvolve a caracterização antropológica.

O homem é dotado de livre arbítrio. Este representa visto por si uma capacidade de opção.

O homem é um ser consciente. Tem consciência do mundo ambiente. Tem consciência dos outros. Tem consciência de si mesmo.

O homem tem a capacidade de colocar a si mesmo fins. A liberdade de escolha permite-lhe prosseguir ou não esses fins.

O homem tem a consciência ética, do bem e do mal. Porque é livre, segue-a ou não. Porque tem a capacidade de optar e conduzir a sua vida, o homem é responsável.

Delineados estes traços muito gerais, observemos que a liberdade humana, no ponto de vista da liberdade moral, não foi particularmente valorada nas sociedades humanas primitivas.

A própria necessidade de defesa perante condições exteriores hostis impôs um gregarismo extremo, em que a individualidade de cada membro ficava submergida pela fortíssima necessidade de coesão do grupo.

Mesmo as civilizações orientais foram totalitárias - abrangiam todos os aspectos da vida do homem, não dando abertura à expansão individual, ainda que por razões éticas, dos seus membros.

A rotura começa a ser operada pela filosofia grega. Por um lado, distinguindo o indivíduo e a pólis. Por outro, cultivando o humanismo. Ainda, valorando a decisão ética - como na morte de Sócrates. Apesar disso, o tema da liberdade aflora escassamente como tema de reflexão.

O outro grande pilar é o cristianismo. Lança a semente da autonomia perante a cidade totalitária, com o Dai a César o que é de César e a Deus o que é de Deus. Firma profundamente o primado da responsabilidade moral. Introduz a dialéctica da realização individual e da comunhão com o próximo.

A partir daí gera-se a elaboração da noção de pessoa, que atingirá a sua plenitude na Idade Média.

Mas a evolução não parou. A partir daí, o voluntarismo crescente, a divisão religiosa, o humanismo renascentista, foram alterando as bases do convívio social. A tolerância religiosa, à medida que se foi firmando, quebrou o monolitismo ideológico.

Estava aberta assim a via para a discussão da posição do súbdito perante o poder, que conduziu à concepção do "contrato social” e subsequentemente à explosão políticoeconómica que tornou o séc. XVIII o século da grande transformação. Do demoliberalismo daí resultante vivemos ainda hoje. 
Mas que traz isso, para a noção de pessoa que deve subjazer aos direitos de personalidade?

Para responder, há que descer mais fundo na indagação da liberdade. Esta não pode limitar-se à seca capacidade de opção. Neste sentido, todo o animal faz opções.

Nem é redutível a um espaço vazio, que o homem pode arbitrariamente preencher - o que representa toda a liberdade de que se ocupou a filosofia política do séc. XVIII. Há que dar o salto do meramente antropológico para o axiológico ${ }^{23}$ - para o homem a quem a liberdade é dada para ser o construtor do seu próprio destino, o que por isso responde pela maneira como o realizar. A liberdade é assim indissociável de uma dimensão ética - por isso para lá do livre arbítrio está a liberdade moral.

Numa outra conjugação dialéctica, o homem é livre para se tornar livre. Ou seja, a liberdade psicológica deve ser instrumento para chegar à liberdade moral. Só isso traz a real conformação da pessoa, a perfeição do modelo que cada um traz em si mas cuja realização lhe está confiada. O homem nasce livre psicologicamente para poder tornarse livre moralmente.

Tudo isto é constitutivo da pessoa, e é a pessoa total que se reflecte no Direito. Por várias facetas.

\section{I - Como sujeito do Direito}

O homem tem necessariamente de ser reconhecido como sujeito, actor na vida jurídica. Poderá haver outras entidades que sejam também acolhidas como sujeitos: o homem não pode deixar de o ser, porque só assim se exprime na vida social a sua autonomia.

\section{II - Como fundamento do Direito}

Todo o Direito é constituído por causa do homem, diziam os romanos já. É porque há homem que o Direito existe. A justificação profunda do Direito encontra-se sempre na realidade da pessoa.

Há outras entidades que são também essenciais na vida social, e portanto exigem igualmente a sua contemplação. Particularmente estão em causa as formações sociais em que o homem necessária ou voluntariamente se integra. Mas essas formações sociais, por mais importantes, são instrumentais. A sua valia, muito grande, reside em última análise em serem indispensáveis para a realização do homem.

\section{III - Fim do Direito}

O homem não só funda o Direito, como este se destina todo a servir o homem. É para a realização do homem que a ordem jurídica existe. A globalidade da sua organização, mesmo nos aspectos mais técnicos, tem o sentido de servir o homem que a integra.

\footnotetext{
${ }^{23}$ Cfr. NEVES, Castanheira. Pessoa, direito e responsabilidade. Rev. Port. de Ciência Criminal, 6-1. (96), 33.
} 


\section{A vertente comunitária}

Mas se é a pessoa ontológica que se afirma perante o Direito, então há que sublinhar o carácter comunitário como essencialmente constitutivo da condição humana.

Este aspecto ficou apagado na versão oitocentista dos direitos do Homem, tal como continua na visão individualista dos direitos de personalidade - particularmente na privacy, como um direito de exclusão dos outros.

Até da nossa exposição anterior, em que avulta o homem como um ens distinctum subsistens, poderia parecer evolar-se uma cisura entre a pessoa e os outros, através da oposição de cada elemento à comunidade em que se integra.

Porém, encontra-se aqui outra síntese dialéctica a traçar, entre o homem que é responsável inteiro do seu próprio destino, mas que ao mesmo tempo só se realiza pela sua integração social.

E aqui, há algo muito mais profundo que a consideração do homem como animal social - portanto, o homem que se agrupa para poder sobreviver e por obediência a um apelo da sua espécie. Porque isso também se observa nos animais. Tem um lastro qualitativo que a diferencia, porque é condição ética da realização da pessoa.

O estar para o outro é assim constitutivo da existência humana ${ }^{24}$. Mas como se reflecte isto sobre o Direito?

É evidente que o Direito está muito longe de poder absorver todo o conteúdo da vertente comunitária do homem. Mas não pode recusar a esta um lugar central, como se fez nos cumes do individualismo.

A dimensão mais imediata daqui resultante é a da solidariedade. O Direito deve servir à construção duma sociedade solidária. A realização do homem a que o direito deve tender como seu fim não é a realização de cada indivíduo isoladamente, no agnosticismo e indiferença pela finalidades prosseguidas; é a realização de cada homem em sociedade, numa comunidade solidária que permita a realização pessoal dos seus membros.

Algumas manifestações desta vertente da pessoa são particularmente significativas.

A Constituição, no art. 26, passou a inscrever o direito ao desenvolvimento da personalidade. A lei civil não o contempla.

À primeira vista é estranho. Parece mesmo que o contrário é que seria o normal. À estruturação política da sociedade é alheio o desenvolvimento que cada um faça de si mesmo, enquanto a lei civil deveria ser-lhe muito mais sensível.

\footnotetext{
${ }^{24}$ Foi colocado de forma impressionante também pelo Evangelho, ao afirmar que o amar opróximo como a si mesmo é semelhante ao mandamento de amar a Deus. Como semelhante, se há uma diferença infinita entre Deus e os homens? Mas o comando é claro, abrindo-nos para um mistério que baliza toda a nossa existência.
} 
Mas meditando um pouco, cremos que está afinal certo.

O direito ao desenvolvimento da personalidade soa estranhamente: a quem pode o homem reclamar o desenvolvimento da personalidade, senão a si próprio? Por isso mesmo não é um direito de personalidade, porque não há um bem da personalidade a que corresponda.

Pelo contrário, admite-se um direito ao desenvolvimento da personalidade como direito fundamental. Tal pode e deve ser a leitura deste art. 26, como dirigido a que sejam criadas condições em que o desenvolvimento da personalidade seja possível. É vago e antes parece representar um superdireito ou direito de cúpula dos outros direitos fundamentais, mas não há motivo para o excluir à partida. Ninguém substitui a pessoa no autodesenvolvimento da personalidade, mas a organização social deve ser propícia ao seu desempenho.

Mas se, nesta medida, é relevante um direito ao desenvolvimento da personalidade, então tem de ser a personalidade substantiva, a personalidade ontológica ou ética, a orientar as opções do legislador, e não apenas a versão negativa e agnóstica, da criação dum espaço onde o arbítrio se possa livremente exercer ${ }^{25}$. Deverá partir da visão da pessoa solidária e da comunidade daí resultante. O que significa que a própria ordem constituída impõe o primado da personalidade substantivamente demarcada ${ }^{26}$.

A prioridade da pessoa implica constantemente a conjugação - a dialéctica - da autonomia pessoal e da integração social. A sociedade é instrumental, mas é nela e por ela que o homem se realiza.

A autonomia surge assim para o Direito enriquecida em relação ao livre arbítrio. A autonomia marca decisivamente a pessoa e tem de ser assegurada, sem o que se ignora

\footnotetext{
${ }^{25}$ Note-se que a Constituição rejeitou a fórmula do livre desenvolvimento da personalidade, consagrando apenas o "direito ao desenvolvimento da personalidade".

${ }^{26}$ PINTO, Paulo Mota. O direito ao livre desenvolvimento da personalidade. In: Portugal - Brasil ano 2000. U.C./Coimbra Editora, 1999, 149 e segs., analisa profundamente o tema. Da previsão do art. 26/1 da Constituição faz derivar um direito geral de personalidade e um direito geral de liberdade. Embora afirme a ligação material à dignidade da pessoa humana, acaba por esvaziar o "desenvolvimento da personalidade" de qualquer conotação ética, limitando-o afinal a espaço vazio em que o sujeito actua como quer. Parece-nos então contraditório que faça derivar duma noção axiologicamente vazia os direitos de personalidade, que pressupõem a noção material de pessoa. Tampouco o direito geral de liberdade nos parece de aplaudir: a liberdade não é decorrência do direito ao desenvolvimento da personalidade, é pressuposto deste, e não cremos que se ganhe algo em transformar a orientação geral, que em princípio a pessoa a nada está obrigada senão em virtude da lei, em direito fundamental; ademais, faria subordinar toda a regra jurídica de conduta ao regime apertado do art. 18/2 da Constituição, como restrição a um direito fundamental, só admissível nos casos expressamente previstos na Constituição. O direito ao desenvolvimento da personalidade só traz algo de novo e útil se tiver densidade ética, protegendo a realização pessoal e não a mera arbitrariedade. Também contrário a um direito geral à liberdade é Joaquim de Sousa Ribeiro, O Problema do Contrato, Almedina, 1999, n. 22, p. 235, que cita Dworkin.
} 
o carácter axiológico e ético da realização pessoal. Mas a própria autonomia não é o valor final, é também um caminho para o fim do desenvolvimento pessoal. Uma "autonomia" assegurada fora de qualquer consideração ética não é autonomia, é arbítrio.

Ilustremos com um exemplo muito simples. Tornou-se uma questão instante a das fontes de células estaminais que possam ser utilizadas na pesquisa e nas terapias que se forem tornando possíveis. Uma fonte eventual é representada pelos produtos de aborto, quer espontâneo quer provocado.

Se o aborto é provocado, afirma-se nos meios médicos a necessidade do consentimento informado da mulher de que provêm. Acrescenta-se mesmo que a informação a prestar inclui que sejam esclarecidas as finalidades da investigação ou terapia a que se destinam.

É uma exigência que não tem nenhum fundamento ético, porque nada tem que ver com a realização dos fins da pessoa.

Esses produtos são considerados hoje como "lixo hospitalar" - deitam-se fora, pura e simplesmente. Se há um aborto provocado, portanto se a gestante quis deitar fora, que sentido teria nesse caso exigir um consentimento em relação àquilo que ela própria terá considerado como lixo? Nada tem que ver com a realização da personalidade, de modo que a subordinação a um consentimento representaria a entrega ao arbítrio, em vez de servir a personalidade ética.

Pelo contrário, a vertente da solidariedade impõe-se aqui sem nenhum entrave. Esses produtos, socialmente importantes, não podem ser desviados da finalidade social. Nenhuma alegação de autonomia em contrário tem suporte ético. É ainda, afinal, a persistência da noção de direito de personalidade como albergue do egoísmo humano que justifica a posição corrente.

Assim se manifesta a dialéctica das finalidades últimas pessoais e da integração social. Os direitos da personalidade devem traduzir que a realização pessoal é indissociável da integração comunitária. Traduzem as exigências de cada pessoa humana no circunstancialismo de cada sociedade, historicamente dada. Devem nortear a necessária busca de consensos na sociedade dividida, com o objectivo de demarcar substantivamente o espaço em que se possa operar a realização pessoal.

\section{As insuficiências dos Direitos de Personalidade}

Até que ponto correspondem os direitos de personalidade, tal como hoje se nos apresentam, à visão substancial da pessoa?

Já chamamos a atenção para os meios extraordinários de defesa que o Código Civil lhes associa; a que acrescem os meios que advêm da normal coincidência com a categoria dos direitos fundamentais. Neste ponto, a orientação legal é adequada. 
Mas em contradição com a posição privilegiada dada a estes direitos está a extensão que se vai fazendo dos direitos de personalidade a aspectos banais, em que nenhum valor ético está em causa. É um aproveitamento oportunístico que ameaça alastrar, à semelhança do que acontece com a categoria dos direitos fundamentais. Apóia-se na visão positivista dos direitos de personalidade como uma categoria formal como qualquer outra, bem como na tendência da nossa sociedade dominada pelo mercado de tudo transformar em fontes de proventos.

É necessário vencer também a ilusão dos consensos. Os consensos são necessários, mas não são critério de verdade: só concepções extremadas da democracia o poderiam sustentar $^{27}$. A sociedade da lisonja em que vivemos não se conforma com os aspectos éticos, antes lhes é hostil. Os grandes elementos da realização ética, a responsabilidade, o sacrifício (até extremo) pelos outros, o valor da vida, são realidades incómodas, que se esquecem na promessa de satisfações egoístas, de êxito na vida, da responsabilidade dos outros...

Porém, nenhuma comunidade subsiste sem uma base de valores comuns que a cimente. Esses valores foram cunhados pela nossa civilização e pela história e, não obstante tantas deturpações, continuam a dar, com mais ou menos consciência por parte daqueles que dela participam, os grandes quadros da vida colectiva. O principal valor é representado antes de mais pelo respeito pela pessoa humana.

Esses valores comuns têm de encontrar tradução no ordenamento social: não há modo de lhes passar de lado. A educação, base da formação humana, supõe necessariamente um sistema de valores. Sem coerção, deve dar substância às matérias que se ministram. Deverá ser adequada à natureza da sociedade concreta em que nos encontramos, porque toda a valoração se faz em concreto: por isso não devemos aceitar a dissolução em cosmopolitismos. Mas a facticidade histórica tem de ser iluminada pela categoria primária da pessoa.

Voltamos a perguntar: a estrutura actual dos direitos da personalidade traduz as exigências da pessoa, dentro da sociedade portuguesa?

Podemos afirmar que está em vias de formação, como um novo ramo do Direito, o ramo dos "Direitos da Personalidade", a autonomizar da Teoria Geral do Direito Civil.

Mas esse ramo, mesmo esquecendo as deturpações assinaladas, está ainda muito longe de traduzir as exigências substanciais da pessoa. Há muitos aspectos essenciais que não estão contemplados.

Isso é logo derivação do objecto expresso deste ramo: os direitos de personalidade.

\footnotetext{
${ }^{27}$ Sobre o significado atribuído ao consenso, cfr. Paulo Ferreira da Cunha, Constituição, Direito e Utopia, U.C./Coimbra Editora, 1996, 424-425 e nt. 1484.
} 
A própria admissibilidade da categoria "direitos de personalidade" foi posta em causa. Contestou-se que a pessoa pudesse ser simultaneamente sujeito e objecto de um direito.

A crítica poderá atingir o pretenso direito geral da personalidade ${ }^{28}$. Mas não inquina os concretos direitos de personalidade, desde que se aceite a reformulação da noção de objecto do direito subjectivo que propomos. A categoria do objecto dos direitos foi "coisificada", de maneira que apenas se ajusta hoje ao objecto dos direitos reais - a coisa. Mas em todos os demais casos o objecto é diferente, porque o objecto é apenas o ponto de referência dos poderes que se outorgam ao titular. Pode ser meramente pensado, como no caso da própria prestação como objecto dos direitos de crédito ${ }^{29}$. Nada tem assim de anómalo que o ponto de referência do direito de personalidade seja um bem da personalidade.

Maiores dificuldades surgem quando se pergunta se a noção de direito da personalidade é susceptível de abarcar todas as figuras que são reclamadas pela protecção da personalidade substantiva.

Para compreender a questão, basta ensaiar perante a trilogia constitucional dos direitos, liberdades e garantias.

As garantias são direitos de personalidade? Ninguém duvida da indispensabilidade das garantias para dar efectividade à tutela. Mas serão direitos? Haverá um direito de personalidade ao babeas corpus? A garantia da greve confere um direito de personalidade?

A questão pode colocar-se ainda com maior acuidade nas liberdades. Uma liberdade é um direito de personalidade? Será correcto falar de um direito à liberdade?

Até porque a liberdade se exprime na maior parte dos casos através de actuações fácticas, não jurídicas. O seu exercício cairá então no domínio do juridicamente indiferente: quer se manifeste por acção ou omissão, não tem efeitos jurídicos ${ }^{30}$. Como configurar então um direito subjectivo? Onde está o bem que, na normalidade das situações ao menos, seria o objecto do direito subjectivo? O centro de gravidade das liberdades está na autonomia. Só aí a liberdade ganha densidade substancial, por permitir o desenvolvimento da personalidade, na linha em que a pessoa prossegue a construção de si mesma.

Há ainda situações que, logo na sua conformação originária, são afastadas da noção de direito subjectivo; e todavia, são muito relevantes na defesa da personalidade.

\footnotetext{
${ }^{28}$ Há quem conclua efectivamente pela vigência de um "direito geral de personalidade", o que é uma construção germânica que não tem nenhuma justificação no nosso ordenamento. Mas não é ponto que careça de debate para os fins que nos propomos.

${ }^{29}$ Cfr. o nosso Direito Civil- Teoria Geral, vol. I cit., n. 196 a 199; vol. III - Relações e Situações Jurídicas, Coimbra Editora, 2002, n. 32 e 33.

${ }^{30}$ As liberdades poderão surgir como o mero reflexo de as condutas não poderem ser impedidas por terceiros.
} 
Pensemos em categorias de interesses juridicamente protegidos, particularmente nos interesses difusos. Estes têm um sentido altruísta: actuando-os, o sujeito beneficia uma comunidade. A vantagem que também ele colhe resulta da sua pertença a essa comunidade. Com essa índole, podem representar aspectos muito importantes da integração comunitária do homem e da realização deste ao serviço da comunidade. Mas como falar então dum direito da personalidade, se logo por definição se esclarece que há um interesse protegido e não um direito subjectivo?

Acima de tudo: se nos centrarmos substancialmente sobre a pessoa, temos de reconhecer que faltam os deveres.

O enquadramento normativo da personalidade, no seu significado substancial, supõe direitos e deveres. Falar só de direitos é ainda um legado do contrato social, do individualismo persistente, tão propício à sociedade da lisonja. Mas axiologicamente é falso, porque atribuir direitos sem deveres é tão ilusório como assegurar o direito à felicidade. A actual Constituição marca um progresso, ao versar sob epígrafe conjunta os direitos e deveres fundamentais.

Se é realmente a pessoa, com a sua inerente dignidade, que ocupa o primado, a disciplina a estabelecer deverá compreender todos estes aspectos, por serem constituintes do estatuto essencial da personalidade.

\section{O Direito da Personalidade}

Há que dar um salto qualitativo. Os direitos da personalidade cumpriram razoavelmente a sua função, de oferecer uma construção que coloca a pessoa humana como núcleo da valoração jurídica. Mas são inidóneos para unificar num ramo do Direito o complexo dos aspectos fundamentais exigidos pela dignidade da pessoa humana.

Há que passar dos direitos de personalidade, que nem sequer foram acolhidos como ramo autónomo do Direito Civil, para o Direito da Personalidade.

Este deverá ser um ramo centrado na pessoa humana e na sua inerente dignidade substantiva. Representará assim na esfera civil a cristalização do princípio da dignidade da pessoa humana para que aponta a Constituição. Densificará, na linha constitucional, esse princípio, depurando-o de todo o formalismo que ameaça hoje os direitos de personalidade.

Por ele se realizará o programa de a pessoa humana ser verdadeiramente tomada como sujeito, fundamento e fim do Direito.

Como não está limitado à categoria técnica dos direitos de personalidade, permitirá enquadrar outras figuras que do mesmo modo contribuam para o estatuto fundamental da pessoa. Poderá recuperar e reconciliar a trilogia constitucional dos direitos, liberdades e garantias, como posições jurídicas activas que tutelam a personalidade. Isso não implica 
porém que tenham todas o mesmo significado, pois a função que desempenham é diversa. As garantias, por exemplo, têm naturalmente carácter instrumental.

Do mesmo modo se incluiriam outras posições activas, como os interesses legítimos, sempre que o seu fulcro fosse a protecção da personalidade.

A isto haverá que fazer acrescer os deveres, porque está em causa a pessoa integral. Os deveres não são anomalias, são emanações vindas da solidariedade. Por exemplo, o dever de socorro, quando não há perigo para o próprio, é uma exigência mínima numa sociedade solidária. Não tem sentido porém fazer uma enumeração exaustiva de deveres essenciais, mas sim a demarcação dos princípios gerais que regem esta matéria. Ainda, permite que os deveres fiquem libertos da marca de excepções, que tem dificultado o progresso neste sector.

Com isto se conseguirá um ramo que apresentará mais que uma colecção de direitos, como se tende a fazer nos direitos de personalidade ${ }^{31}$. Haverá um sistema coerente, que enquadrará a pessoa como ente que se constrói a si mesmo na prossecução de fins próprios, integrado solidariamente em comunidade com outras pessoas.

É este um programa, para um objectivo possível. Não contém sequer um apelo ao legislador: é muito mais um apelo à comunidade jurídica. A prioridade da pessoa é apta para levar à formação dum ramo autónomo, prévio a todos os outros no Direito Privado. Seria Direito Civil, porque o Direito Civil é o Direito comum do homem comum, e não há nada de mais comum que a personalidade humana.

Também não há pressa: a pressa está só na tomada de consciência. Levaria antes de mais a colocar o estudo da pessoa como premissa de todo o Direito Civil, o que lamentavelmente não é ainda praticado por todos. Depois, progressivamente, permitiria formar o sistema coerente da armadura jurídica básica da personalidade humana.

\section{Referências}

ASCENSÃO, J. Oliveira. Direito civil. Teoria geral. Introdução. As pessoas. Os bens. 2. ed. Coimbra: Coimbra Editora, 2000. n. 53-55. v. 1.

ASCENSÃO, J. Oliveira. Direito civil. Teoria geral. Relações e situações jurídicas. Coimbra: Coimbra Editora, 2002. n. 32-33. v. 3.

CANOTILHO, J. J. Gomes. Direito constitucional e teoria da Constituição. 5. ed. Almedina, 2002.

CAStanheira NeVES. Pessoa, direito e responsabilidade. Rev. Port. de Ciência Criminal, 6-1. (96), 33.

CUNHA, Paulo Ferreira da. Constituição, direito e utopia. U.C. / Coimbra Editora, 1996.

\footnotetext{
${ }^{31}$ Ou sequer de direitos e de deveres.
} 
José de Oliveira Ascensão

KELSEN, Hans. Teoria pura do direito.

MODERNE Frank. La dignité de la personne comme principe constitutionnel dans les Constitutions portugaise et française. In: MIRANDA, Jorge (Coord.). Perspectivas constitucionais. Nos 20 anos da Constituição de 1976. Coimbra: Coimbra Editora, 1996.

OTERO, Paulo. A democracia totalitária. Principia, 2001, n. 8.2.3.

PINTO, Paulo Mota. O direito ao livre desenvolvimento da personalidade. In: Portugal - Brasil Ano 2000. U.C. / Coimbra Editora, 1999.

RIBEIRO, Joaquim de Sousa. O problema do contrato. Coimbra: Almedina, 1999. n. 22 .

SOUSA, Rabindranath Capelo de. O direito geral de personalidade. Coimbra: Coimbra Editora, 1995. 